\title{
Tissue Engineered Osteogenesis in Bone Defects by Homologous Osteoblasts Loaded on Sterile Bioresorbable Coral Scaffold in Rabbits
}

\author{
Arvind Tripathi ${ }^{1}$, Pandruvada Subramanya Narayana Murthy ${ }^{2}$, Govind Keshri $^{3}$, Man Mohan Singh ${ }^{1}$ \\ ${ }^{1}$ Saraswati Dental College and Hospital, Faizabad Road, Lucknow, India \\ ${ }^{2}$ Institut des Recherches Cliniques de Montreal, Montreal, Canada \\ ${ }^{3}$ C-406, Indira Nagar, Lucknow, India \\ E-mail: atrip2006@gmail.com, singhmm46@gmail.com \\ Received January 11, 2011; revised June 28, 2011; accepted August 18, 2011
}

\begin{abstract}
Objectives: This study explores feasibility of tissue-engineered osteogenesis using sterile coral implants loaded with homologous osteoblasts to repair bone defects. Study Design: A unilateral $4 \mathrm{~mm}$ transverse discontinuity defect was produced approximately mid-way along left radius of young female rabbits using rotary diamond disc under continuous saline irrigation and stabilised with autoclaved steel miniplate and screws. The defect was then fitted with sterile bioresorbable coral implant loaded with homologous neonatal calvarial osteoblasts or control implants without osteoblasts. All animals underwent radiography immediately post-operative, at weekly intervals for four weeks and at fortnightly intervals thereafter. Operated bones were histologically evaluated for osteogenesis at 12 weeks. Results: Findings demonstrate osteogenesis and complete repair of bioresorbable coral implant by homologous osteoblasts loaded on coral scaffold. Conclusions: Single stage surgery using this technique to induce osteogenesis and closure of discontinuity bone defects including palatal clefts and peripheral reduction of large craniofacial defects might prove better therapeutic modality than autologous bone grafting or tissue distraction osteogenesis.
\end{abstract}

Keywords: Osteogenesis, Homologous Neonatal Calvarial Osteoblasts, Bioresorbable Coral Scaffold, Discontinuity Bone Defects, Rabbit

\section{Introduction}

Until the beginning of $20^{\text {th }}$ century, amputation was the only practical solution to treat large bony defects considered incurable leading to devastating trauma and side effects for the patient [1]. Later advances led to the development of techniques like autologous bone and free vascularised fibular grafting, still considered as gold standard with most favorable outcome, to facilitate treatment of bone defects [2]. While allogenic grafts as well as synthetic bone substitutes [3] have been used to fill voids, this approach appeared successful only for small bone defects.

Osteogenesis is a complex physiological process. It involves coordinated participation of haemopoietic and immune cells within the bone marrow in conjunction with vascular and skeletal cell precursors [4]. It is dependant on adequate number of osteoblasts, which are recruited predominantly from the local bone marrow and periosteal cambial layer. Tissue engineered bone generation has been considered as an effective tool in osteogenesis and closure of bone defects including palatal clefts and peripheral reduction of large craniofacial defects [5]. Use of scaffolds of synthetic as well as natural biomaterials has also been tried to promote migration, proliferation and differentiation of bone cells [6]. Previous studies have proved that natural coral exoskeleton, because of its interconnected porous structure, like the spongy bone, has superior mechanical properties of calcium-based ceramic [7]. Transcortical bony defects implanted with coral have been reported to become vascularised and display osteogenesis with concurrent resorption of the coral implant [8]. Such scaffolds, however, lack osteogenic and osteoinductive potential of bone grafts [7]. Recent tissue engineering with the use of embryonic stem cells has demonstrated their capability to 
adopt various cell fates and facilitate development and regeneration of various tissues [9]. Stromal compartment of bone marrow contains many multi-potential mesenchymal stem cells (MSCs) [10], which can be induced to differentiate into osteoblasts to form new bone. Available evidence shows that MSC-loaded implants can elicit true bone regeneration with complete disappearance of the biomaterial and formation of cortical bone in a bone defect of clinically relevant volume [11]. However, since the use of stem cells for treatment might involve ethical considerations in clinical settings [12] together with limited availability of osteogenic fresh autologous grafts [13], use of proliferating homologous ultimate bone forming cells or osteoblasts delivered on a resorbable natural biomaterial scaffold to induce osteogenesis in critical bone defects was hypothesized and forms the basis of this study.

\section{Materials and Methods}

\subsection{Animals and Chemicals}

Fourteen neonatal (1 - 3 days old) and fourteen young (60 days old) female New Zealand white rabbits (body weight: $600 \pm 100 \mathrm{~g}$ ) maintained under standard conditions $\left(22^{\circ} \mathrm{C} \pm 1^{\circ} \mathrm{C}\right)$ with alternate $12 \mathrm{~h}$ light/dark periods and free access to regular pellet diet (Lipton India Ltd., Bangalore) and tap water were used in this study. This study was conducted at the Central Drug Research Institute, Lucknow, India. The Animal Ethical Committee of the Institute approved the protocol with respect to the humane care and treatment of animals used in this study.

Minimum essential medium ( $\alpha$-MEM), collagenase, dispase, fetal calf serum (FCS), glutamine, penicillinstreptomycin, nonessential amino acid solution, sodium pyruvate, sodium $\beta$-glycerophosphate, ascorbic acid, naphthol AS-MX-phosphate, ethylene glycol monomethyl ether, Fast-Red TR salt, were purchased from Sigma-Aldrich, St. Louis, MO, trypsin-EDTA (ethylene diamine tetra acetic acid) from Gibco Life Sciences, Grand Island, NY. All other chemicals were of analytical grade. Coral exoskeleton (Porites spp,) generously provided by the Central Marine Fisheries Research Institute, Kochi, India was identified by the Botany Department of the Institute.

\subsection{Coral Implant Preparation}

Cylindrical pieces (Figure 1) of the coral exoskeleton were cut on a Rotary Diamond Disc mounted on a Dental Micromotor Handpiece (NSK, Japan) with continuous physiological saline $(0.85 \%$ sodium chloride in distilled water) spray. The coral pieces were sterilized by autoclaving and used as implants.

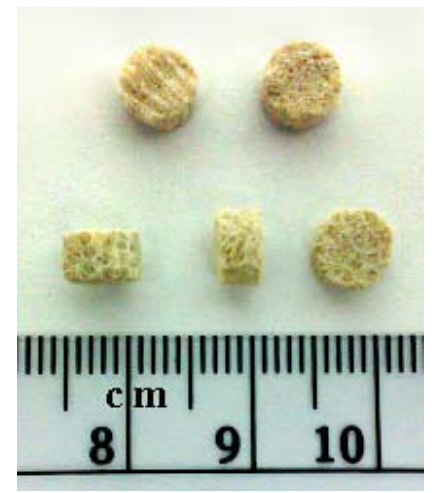

Figure 1. Cylindrical pieces of the coral exoskeleton (Porites spp.) cut on a Rotary Diamond Disc mounted on a Dental Micromotor Handpiece with continuous physiological saline spray.

\subsection{Primary Osteoblast Cell Culture}

Neonatal rabbit calvarial cell cultures (Figure 2) were established as described previously $[14,15]$ with slight modifications. Briefly, frontal and parietal bones from rabbit neonates ( 1 - 3 day old) were digested in $0.2 \%$ collagenase $/ 0.2 \%$ dispase in $\alpha \mathrm{MEM}$ to obtain 5 sequential digests. The second through fifth digests were com-

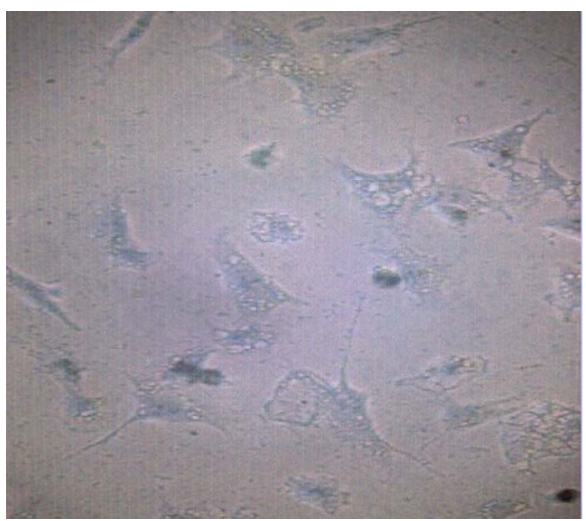

(a)

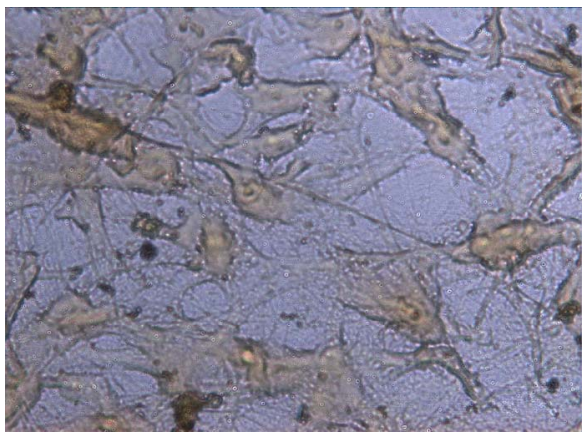

(b)

Figure 2. Neonatal rabbit calvaria derived primary osteoblast cells (a) and showing alkaline phosphatase expression (b) 7 days after culture in defined medium. 
bined, resuspended and grown to confluence at $37^{\circ} \mathrm{C}$ and $5 \% \mathrm{CO}_{2}$ in air in $\alpha$ MEM supplemented with $10 \%$ fetal bovine serum (FBS), $20 \mathrm{mM}$ glutamine, $100 \mathrm{U} / \mathrm{ml}$ penicillin-streptomycin, $0.1 \mathrm{mM}$ non-essential amino acid solution, $1 \mathrm{mM}$ sodium pyruvate, $10 \mathrm{mM}$ sodium $\beta$ glycerophosphate and $50 \mu \mathrm{g} / \mathrm{ml}$ ascorbic acid. Culture medium was changed every $48 \mathrm{~h}$. Cells were then trypsinised and approximately $2 \times 10^{6}$ cells were loaded onto each autoclaved coral implant and cultured for $12 \mathrm{~h}$ for the cells to adhere to the coral implants. The proliferation, differentiation and viability of cells in culture was confirmed by alkaline phosphatase staining, an early stage osteoblast differentiation marker. Pertinently, calvaria derived primary osteoblast cultures are considered $>95 \%$ pure cell population [16]. For alkaline phosphatase (ALP) expression, the cells were plated at $10^{4}$ cells per cover slip (6 mm diameter, Thermanox, Nunc, USA) and cultured for 7 days in 96-well plates, fixed in $4 \%$ formaldehyde in phosphate buffered saline (PBS) and incubated with the substrate $(5 \mathrm{mg}$ naphthol AS-MX phosphate, $0.25 \mathrm{ml}$ ethylene glycol monomethyl ether and 10 mg Fast red TR in $24 \mathrm{~mL} \mathrm{0.1} \mathrm{M} \mathrm{TBS,} \mathrm{pH} \mathrm{9.5)} \mathrm{for} 1 \mathrm{~h}$ at room temperature. Representative images were captured using Leica DC 300 camera and Leica IM50 Image Acquisition software fitted to a Leica DMLB microscope.

\subsection{Osteotomy}

A unilateral discontinuity defect was produced in one radius bone of each young female rabbit by standardized surgical procedure under Ketamine (125 mg, i.m.) short acting anaesthesia. For this purpose, forearm of each rabbit was shaved and swabbed with Povidone-Iodine solution (Betadine Lotion, Win Medicare India Ltd., New Delhi). About $5 \mathrm{~cm}$ longitudinal incision was made to expose the radius bone. Approximately mid-way along its length, a $4 \mathrm{~mm}$ transverse discontinuity defect was produced using a Rotary Diamond Disc (Horico-Hopf Ringleb, GmbH, Germany) under continuous sterile PBS irrigation at room temperature to prevent thermal necrosis of the margins and stabilised with autoclaved steel miniplate and screws. The debris was removed by flushing with the physiological saline. The dissected limb was immediately stabilized with the help of an autoclaved steel bone miniplate and screws $(6 \mathrm{~mm}$ length, $1.5 \mathrm{~mm}$ diameter; 2 screws on each side of the defect; Figures 3-5) and tightened with an implant screwdriver. Animals were then randomized into two groups of seven each. Animals of Group I received sterile coral implants loaded with homologous osteoblasts, whereas animals of Group II received sterile coral implants without osteoblasts in a similar manner. Care was taken to ensure a snug fit of the implant into the discontinuity defect without side projections. The incision was then sutured
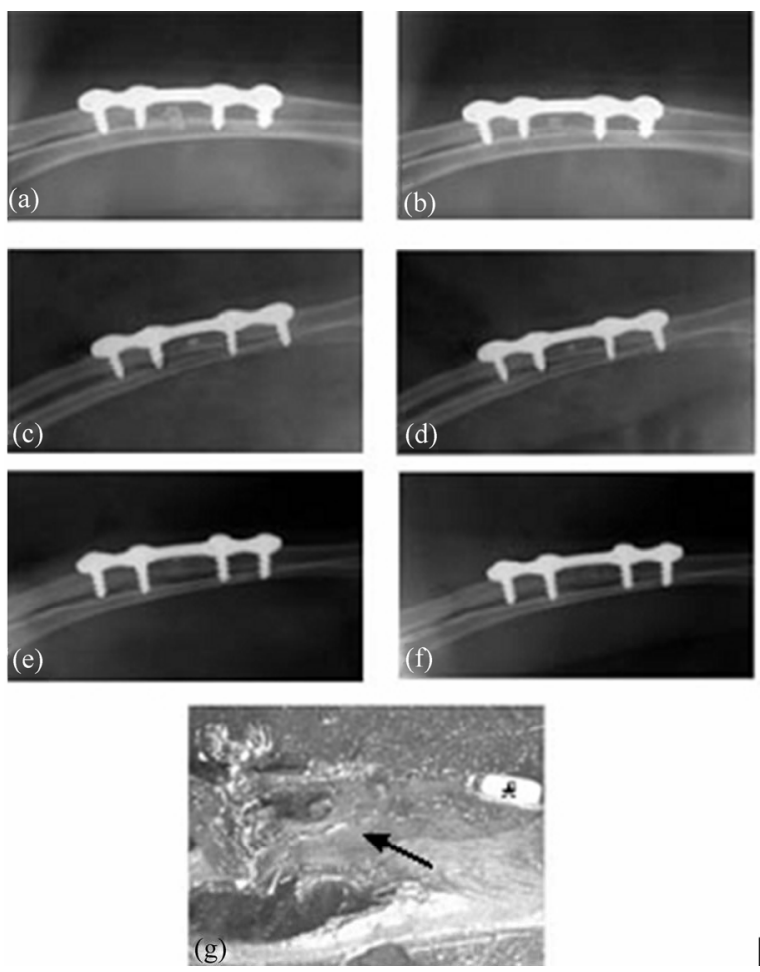

Figure 3. Radiographs of left forearm of a rabbit (\#7; Group I) with unilateral discontinuity defect in radius bone fitted with sterile coral implant loaded with homologous osteoblasts taken immediately post-operative (a) and at 4 (b), 6 (c), 8 (d), 10 (e) and 12 (f) weeks thereafter. Steel bone miniplate and screws used to stabilize the dissected limb are visible in the radiographs. Note progressive osteogenesis with increasing intervals post-surgery and concurrent reduction in size of the coral implant. While the coral implant was almost completely resorbed at $10 \pm 1$ weeks, complete repair (arrow) of the discontinuity bone defect was observed at 12 weeks $(f, g)$. This status was observed in 5 of the 7 rabbits of this group. Histological picture (g) also shows stabilizing screw $(*)$

with 3.0 silk (Ethicon, Johnson and Johnson, USA) followed by dressing with surgical gauge and Micropore adhesive tape (3M India-Bangalore) after application of Mupirocin cream (T-Bact, Smith-Kline \& French, India, Mumbai).

\subsection{Radiography, Tissue Retrieval and Histology}

Radiographs of each bone were taken immediately post-operative, at weekly intervals for 4 weeks after surgery and at fortnightly intervals thereafter. Paralleling cone technique (70 Kvp, $8 \mathrm{~mA}$ Machine-Explor-X, VILLA, Italy) with a 0.7 sec exposure time was used. Animals were autopsied at 12 weeks post-surgery by excessive ether inhalation. Operated radial bones from each animal were carefully dissected free of adhering 

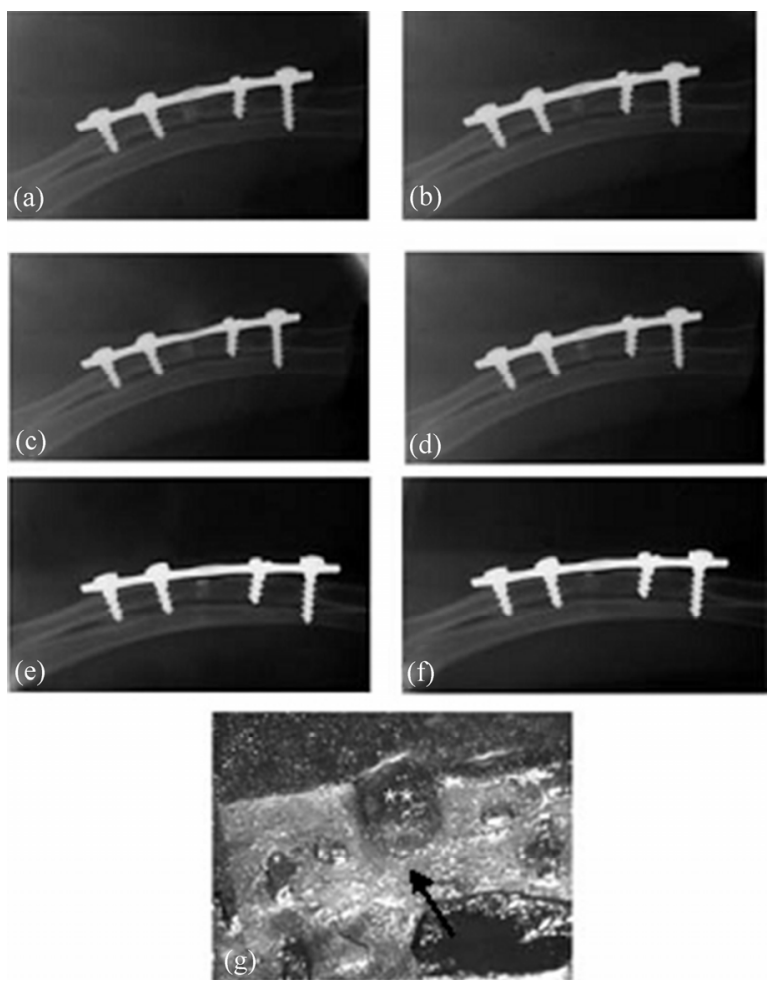

Figure 4. Radiographs of left forearm of a rabbit (\#3; Group I) with unilateral discontinuity defect in the radius bone fitted with sterile coral implants loaded with homologous osteoblasts taken immediately post-operative (a) and at 4 (b), 6 (c), 8 (d), 10 (e) and 12 (f) weeks after surgery. Steel bone miniplate and screws used to stabilize the dissected limb are visible in the radiographs. Note only partial bone formation (arrow) with gradual resorption and ejection of the implant $(* *)$ at 12 weeks post-surgery (f) (g). This status was observed in only 2 of the 7 rabbits of this group.

tissue and fixed in 70\% ethanol for histology. Undecalcified isolated radial bones were dehydrated using ascending gradations of isopropanol, cleared in acetone and embedded in clear self-cure Polymethyl-Methacrylate following standard procedure [17]. Resin blocks were cut into $50 \mu \mathrm{m}$ thick longitudinal sections using a diamond-wafering blade fitted to Isomet low speed saw (Buehler, USA). Images of unstained sections were captured using Leica DC 300 camera and Leica IM50 Image Acquisition Software fitted to Leica S6D microscope to monitor the extent of healing in each animal.

\section{Results}

\subsection{Osteoblast Cell Cultures and ALP Expression}

The cells (Figure 2(a) and (b)) attained $>70 \%$ confluency after 7 days of culture and exhibited intense ALP staining.
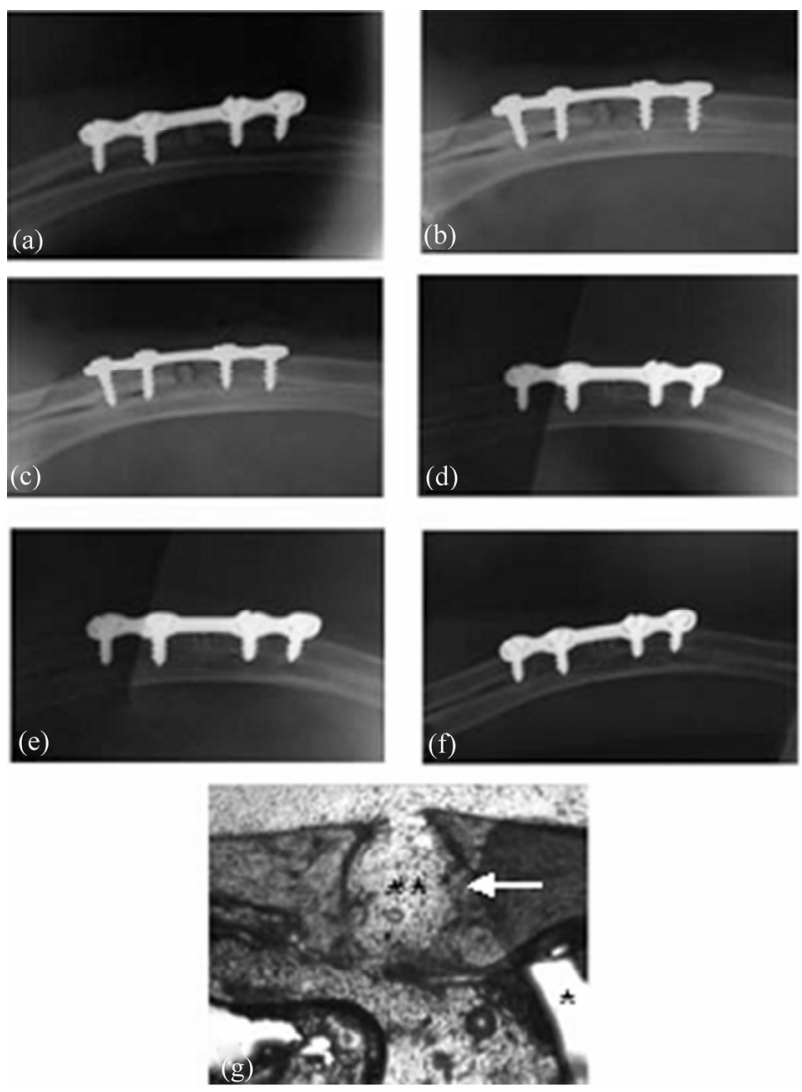

Figure 5. Radiographs of left forearm of a rabbit (\#10; Group II) with unilateral discontinuity defect in the radius bone fitted with empty coral implant (i.e., without osteoblasts) taken immediately post-operative (a) and at 4 (b), 6 (c), 8 (d), 10 (e) and 12 (f) weeks after surgery. Steel bone miniplate and screws used to stabilize the dissected limb are visible in the radiographs. Note minimal bone formation and absence of complete bone union. The coral implants $(* *)$ did not resorb fully even 12 weeks after surgery (f,g). Partial bone formation (arrow) with implant loosening (because of partial resorption) is, however, evident (g). Coral implant is surrounded by fibrous connective tissue aggregation. This status was observed in all the 7 rabbits of this group. Histological picture (g) also shows stabilizing screw (*).

\subsection{Osteogenesis}

Marked differences in the extent of osteogenesis were observed between the two groups of animals. In animals with discontinuity defects fitted with coral implants loaded with homologous osteoblasts (Group I), osteogenesis was observed at around $4 \pm 1$ weeks post-surgery (Figure 3(b)) and bone formation was near complete with defects appearing radiolucent at $6 \pm 1$ weeks (Figure 3(c)). Concurrent with osteogenesis, coral implants displayed resorption and reduction in size and were almost completely resorbed at $10 \pm 1$ weeks (Figure 3(e)). In five of the animals of this group, the bone defect was 
completely filled with new bone (Figure 3(f) and (g)), while in two animals, partial bone formation with gradual resorption and ejection of the implant was observed (Figure 4(a)-(g)).

In all the 7 animals of Group II fitted with sterile coral implants without osteoblasts (Figure 5(a)-(g)), osteogenesis was generally minimal and complete bone union, as observed in animals of Group I, did not occur in any animal. The coral implants, too, did not get fully resorbed in any animal even 12 weeks post-surgery. Partial bone formation with loosening of implants due to partial resorption was, however, evident. Coral implants in animals of this group were generally surrounded by fibrous connective tissue aggregation.

\section{Discussion}

Results of the present study provide evidence of tissue engineered osteogenesis and complete repair of small discontinuity defect in radial bone of rabbits by confluent homologous calvarial osteoblasts loaded on sterile bioresorbable coral scaffold. Pertinently, bone tissue engineering, combining the application of principles of orthopedic surgery with basic science and engineering has been heralded as an alternative to bone regeneration to replace or restore the function of traumatized, damaged or lost bone [18].

Critical bone defects fail to heal because of perturbations at the site of fracture [19]. This led to the use of a variety of materials such as hydroxyapatite, tricalcium phosphate, hyaluronic acid based polymer, decalcified bone and chondroid bone for osteoinduction in animal models [20-22]. However, the main drawback of use of such implants was their slow resorption, producing bony ingrowth onto a porous surface rather than true bone generation [23]. Recent tissue engineering approaches have attempted to repair cartilage and bone defects based on mesenchymal stem cells (MSCs) seeded onto porous ceramic scaffolds [24]. Compared to harvesting bone grafts, needle aspiration of bone marrow offers a simple, minimally traumatic and rich source of MSCs in the infant patient minimizing morbidity. These cells have the potential to differentiate into bone, cartilage, marrow element, fat and connective tissue. A series of studies [25] have strongly indicated the feasibility of porous natural coral as scaffold material transplanted with marrow derived osteoblasts for osteogenesis. Al-Salihi and Samsuddin [26] have demonstrated that the natural coral implant provided excellent and favorable situation for bone marrow cells to differentiate into osteoblasts that could lead to formation of a large amount of mineralized tissue on the coral surface. In an attempt to regenerate bone, Petite et al. [11] used sea coral, a natural calcium car- bonate based ceramic, in combination with autologous MSCs to produce orthopedic implants that facilitated healing of bony defects in sheep. Over the course of four months of implantation, these coral-stem cell composites were remodeled into radiographically mature bone and, in some cases, demonstrated complete unification with native bone on either side of the composite. Moreover, the results were superior to those observed when coral was implanted alone, or in combination with an aspirate of fresh bone marrow rather than with stem cells. These investigators speculated that formation of mature bone from coral-stem cell composite could be attributed to degradable nature of the natural ceramic matrix, as well as to interconnectedness of the matrix pores that allowed infiltration of the bone precursor cells.

According to Guillemin [27], Porites coral scaffold, as used in the present study, with an average pore size of $250 \mu \mathrm{m}$ and an interconnected structure with no dead end pockets should facilitate vascular invasion and new bone formation. As osteogenesis progressed, the coral implant displayed resorption and reduction in size. This suggested conduction of bone marrow cells through the coral implant and their participation in coral resorption. Pertinently, while use of MSCs has the advantage over osteoblasts, for giving rise to cells of multilineage contributing to fracture healing, homologous/autologous osteoblasts provide a potential source for skeletal tissue engineering. Wang et al. [28] have reported better new bone growth using perfusion culture of marrow derived osteoblasts on porous ceramic substrates.

Bone generation by autologous cell transplantation in combination with biodegradable scaffold is also one of the most promising techniques being developed in craniofacial surgery [29]. Despite continued efforts at improving various surgical techniques to achieve superior functional outcome and aesthetic results in palatal clefts defects, complications such as postoperative bleeding, graft rejection and wound dehiscence leading to fistulae have continued to challenge the surgeons. The therapeutic hypothesis in our study was to put a bioresorbable organic implant, conforming to the size of the palatal cleft as estimated from a preoperative occlusal radiograph loaded with homologous osteoblasts such that as the implant resorbed, tissue engineered osteogenesis would close the defect. Advantages of such an approach over autologous bone grafting or tissue distraction osteogenesis include single stage surgery, unhampered sutural and midfacial growth and development of proper velopharyngeal sphincter vital to normal speech.

Healing time is a major concern in tissue repair. In the present strategy, it was presumed that confluent osteoblasts might initiate osteogenesis faster than their immature pluripotent precursors. This is despite the ini- 
tial cell death due to lack of vascularisation within the implant resulting in impeded action of osteoblasts. During the repair process, the pathway of normal embryonic development is recapitulated with coordinated participation of several cell types [30]. Currently, as the molecular and cellular events during the cascade of osteogenesis are being better understood, newer three-component strategies [31] are being devised and tested in order to promote bone formation/healing. In essence, tissue engineering aims to combine progenitor cells such as MSCs or mature osteoblasts for osteogenesis with biocompatible materials or scaffolds for osteoinduction and appropriate growth factors and/or certain osteogenic agents [21] for osteoconduction to be able to generate and maintain bone [29]. This new strategy though offers great potential for treatment of conditions requiring bone repair, needs detailed investigation so that tissue engineered osteogenesis becomes a viable and simple therapy option for bone defects including cleft palate and other craniofacial defects minus the need of repetitive attempts at repair and consequent adverse effects of scarring, impeded bone growth and bone fusion failure.

\section{Acknowledgements}

The authors gratefully acknowledge the help offered by the Botany Department of CDRI, Lucknow, India for identification and Director, Central Marine Fisheries Research Institute, Kochi, India for providing the coral exoskeleton (Porites spp.) and the Ministry of Health and Family Welfare, Government of India, New Delhi for financial support. PSNM thanks the Council of Scientific \& Industrial Research, New Delhi for award of Senior Research Fellowship and MMS thanks the Indian Council of Medical Research, New Delhi for appointment as Emeritus Medical Scientist. Approval of the Institutional Review Board for its publication has been obtained and the manuscript has been assigned communication number 7634 .

\section{References}

[1] M. Laitinen, J. Hardes, H. Ahrens, C. Gebert, B. Leidinger, et al., "Treatment of Primary Malignant Bone Tumours of the Distal Tibia," International Orthopaedics, Vol. 29, No. 4, 2005, pp. 255-259. doi:10.1007/s00264-005-0656-4

[2] C. J. Damien and J. R. Parsons, "Bone Graft and Bone Graft Substitutes: A Review of Current Technology and Applications," Journal of Applied Biomaterials, Vol. 2, No. 3, 1991, pp. 187-208. doi:10.1002/jab.770020307

[3] P. Castellon and R. A. Yukna, "Immediate Dental Implant Placement in Sockets Augmented with HTR Synthetic Bone,” Implant Dentistry, Vol. 13, No. 1, 2004, pp.

\section{2-48. doi:10.1097/01.ID.0000116451.04676.7B}

[4] H. Sun, Z. Qu, Y. Guo, G. Zang and B. Yang, "In vitro and in vivo Effects of Rat Kidney Vascular Endothelial Cells on Osteogenesis of Rat Bone Marrow Mesenchymal Stem Cells Growing on Polylactide-Glycoli Acid Scaffolds," BioMedical Engineering Online, Vol. 6, 2007, p. 41. doi:10.1186/1475-925X-6-41

[5] J. T. Schantz, S. H. Teoh, T. C. Lim, M. Endres, C. X. Lam, et al., "Repair of Calvarial Defects with Customized Tissue-Engineered Bone Grafts I. Evaluation of Osteogenesis in 3-Dimensional Culture System,” Tissue Engineering, Vol. 9, Supplement 1, 2003, pp. S113-S126. doi:10.1089/10763270360697021

[6] D. W. Hutmacher and A. J. Garcia, "Scaffold-Based Bone Engineering by Using Genetically Modified Cells," Gene, Vol. 347, No. 1, 2005, pp. 1-10.

[7] C. Demers, C. R. Hamdy, K. Corsi, F. Chellat, M. Tabrizian, et al., "Natural Coral Exoskeleton as a Bone Graft Substitute: A Review,” Bio-Medical Materials and Engineering, Vol. 12, No. 1, 2002, pp. 15-35.

[8] J. C. Fricain, J. Alouf, R. Bareille, F. Rouais and J. L. Rouvillain, "Cytocompatibility Study of Organic Matrix Extracted from Caribbean Coral Porites astroides," Biomaterials, Vol. 23, No. 3, 2002, pp. 673-679.

[9] L. Gepstein, "Derivation and Potential Applications of Human Embryonic Stem Cells,” Circulation Research, Vol. 91, No. 10, 2002, pp. 866-876. doi:10.1161/01.RES.0000041435.95082.84

[10] M. E. Owen, J. Cave and C. J. Joyner, "Clonal Analysis in Vitro of Osteogenic Differentiation of Marrow CFUF," Journal of Cell Science, Vol. 87, No. 5, 1987, pp. 731-738.

[11] H. Petite, V. Viateau, W. Bensaid, A. Meunier, C. de Pollak, et al., "Tissue Engineered Bone Regeneration," Nature Biotechnology, Vol. 18, No. 9, 2000, pp. 959-963. doi:10.1038/79449

[12] G. Bahadur, "Ethics of Testicular Stem Cell Medicine," Human Reproduction, Vol. 19, No. 12, 2004, pp. 27022710. doi:10.1093/humrep/deh538

[13] J. Glowacki and J. B. Mulliken, "Demineralised Bone Implants,” Tissue Engineering, Vol. 11, Supplement 4, 2005, pp. 5113-5126.

[14] N. J. Horwood, J. Elliott, T. J. Martin and M. T. Gillespie, "Osteotropic Agents Regulate the Expression of Osteoclast Differentiation Factor and Osteoprotegerin in Osteoblastic Stromal Cells,” Endocrinology, Vol. 139, No. 11, 1998, pp. 4743-4746.

[15] R. Maurya, G. Singh, D. K. Yadav, B. Biju, P. S. N. Murthy, et al., "Osteogenic Activity of Constituents From Butea Monosperma,” Bioorganic Medicinal Chemistry Letters, Vol. 19, No. 3, 2008, pp. 610-613. doi:10.1016/j.bmcl.2008.12.064

[16] G. L. Wong and D. V. Cohn, "Target Cells in Bone for Parathormone and Calcitonin Are Different: Enrichment for Each Cell Type by Sequential Digestion of Mouse Calvaria and Selective Adhesion to Polymeric Surfaces," Proceedings of the National Academy of Sciences, Vol. 
72, No. 8, 1995, pp. 3167-3171. doi:10.1073/pnas.72.8.3167

[17] R. Fossaceca, M. Di Terlizzi, A. Stecco, L. Canalis, F. Travaglini, et al., "MRI Post-Vertebroplasty," La Radiologia Medica, Vol. 112, No. 2, 2007, pp. 185-194. doi:10.1007/s11547-007-0134-8

[18] F. R. Rose and R. O. Oreffo, "Bone Tissue Engineering: Hope vs Hype," Biochemical Biophysical Research Communications, Vol. 292, No. 1, 2002, pp. 1-7. doi:10.1006/bbrc.2002.6519

[19] J. Y. Huh, B. H. Choi, B. Y. Kim, S. H. Lee, S. J. Zhu, et al., "Critical Size Defect in the Canine Mandible," Oral Surgery Oral Medicine Oral Pathology Oral Radiology and Endodontology, Vol. 100, No. 3, 2005, pp. 296-301.

[20] T. Kawata, S. Kohno, T. Fujita, H. Sugiyama, C. Tokimasa, et al., "New Biomaterials and Methods for Craniofacial Bone Defect: Chondroid Bone Grafts in Maxillary Alveolar Clefts," Journal of Craniofacial and Genetics Developmental Biology, Vol. 20, No. 2, 2000, pp. 4952.

[21] G. Lisignoli, M. Fini, G. Giavaresi, A.N. Nicoli, S. Tonneguzzi, et al., "Osteogenesis of Larger Segmental Radius Defects Enhanced by Basic Fibroblast Growth Factor Activated Bone Marrow Stromal Cells Grown on Non-Woven Hyaluronic Acid-Based Polymer Scaffold,” Biomaterials, Vol. 23, No. 4, 2002, pp. 1043-1051.

[22] A. K. Gosain, P. A. Riordon, L. Song, M. T. Amarante, B. Kalantarian, et al., "A 1-Year Study of Osteoinduction in Hydroxyapatite-Derived Biomaterials in an Adult Sheep Model: Part II. Bioengineering Implants to Optimize Bone Replacement in Reconstruction of Cranial Defects,” Plastic and Reconstructive Surgery, Vol. 114, No. 5, 2004, pp. 1155-1163. doi:10.1097/01.PRS.0000135852.45465.A9

[23] S. Kadiyala, N. Jaiswal and S Bruder, "Culture Expanded Bone Marrow-Derived Mesenchymal Stem Cells Can Regenerate a Critical Sized Segmental Bone Defect,” Tissue Engineering, Vol. 3, No. 2, 1997, pp. 173-185. doi:10.1089/ten.1997.3.173

[24] M. B. Nair, H. K. Varma, K. V. Menon, S. J. Shenoy and A. John, "Tissue Regeneration and Repair of Goat Seg- mental Femur Defect with Bioactive Triphasic Ceramic-Coated Hydroxyapatite Scaffold,” Journal of Biomedical Materials Research, Part A, Vol. 91A, No. 3, 2008, pp. 855-865. doi:10.1002/jbm.a.32239

[25] F. Chen, S. Chen, K. Tao, X. Feng, Y. Liu, et al., "Marrow-derived osteoblasts seeded into porous natural coral to prefabricate a vascularised bone graft in the shape of a human Mandibular ramus: Experimental study in rabbits,” British Journal of Oral and Maxillofacial Surgery, Vol. 42, 2004, 532-537.

[26] K. A. Al-Salihi and A. R. Samsuddin, "Bone Marrow Mesenchymal Stem Cells Differentiation and Proliferation on The Surface of Coral Implants," Medical Journal of Malaysia, Vol. 59, Supplement B, 2004, pp. 200-201.

[27] G. Guillemin, “Comparison of Coral Resorption and Bone Apposition with Two Natural Corals of Different Porosities," Journal of Biomedical Materials Research, Vol. 23, No. 7, 1989, pp. 765-779. doi:10.1002/jbm.820230708

[28] Y. Wang, T. Uemura, J. Dong, H. Kojima, J. Tanaka, et al., "Application of Perfusion Culture System Improves in Vitro and in Vivo Osteogenesis of Bone Marrow-Derived Osteoblastic Cells in Porous Ceramic Materials," Tissue Engineering, Vol. 9, 2003, pp. 1205-1214. doi:10.1089/10763270360728116

[29] J. T. Schantz, S. H. Teoh, T. C. Lim, M. Endres, C. X. Lam, et al., "Repair of Calvarial Defects with Customised Tissue-Engineered Bone Grafts I. Evaluation of Osteogenesis in a 3-Dimensional Culture System,” Tissue Engineering, Vol. 9, Supplement 1, 2003, pp. S113-S126. doi:10.1089/10763270360697021

[30] C. Fergusson, E. Alpern, T. Miclau and J. A. Helms, "Does Adult Fracture Repair Recapitulate Embryonic Skeletal Formation?” Mechanisms of Development, Vol. 87, No. 1-2, 1999, pp. 57-66. doi:10.1016/S0925-4773(99)00142-2

[31] Y. Khan, M. J. Yaszemski, A. G. Mikos and C. T. Laurencin, "Tissue Engineering of Bone: Material and Matrix Considerations," Journal of Bone and Joint Surgery, American, Vol. 90, Supplement 1, 2008, pp. 36-42. doi:10.2106/JBJS.G.01260 